\title{
Current Approaches to the Diagnosis and Treatment of Polycystic Ovarian Syndrome in Youth
}

\author{
Katerina Harwood Patricia Vuguin Joan DiMartino-Nardi \\ Division of Pediatric Endocrinology, Department of Pediatrics, Children's Hospital at Montefiore Medical Center, \\ Bronx, N.Y., USA
}

\section{Key Words}

Polycystic ovary syndrome - Ovarian ultrasound ·

Life-style changes

\begin{abstract}
Polycystic ovary syndrome (PCOS) is one of the most common endocrinopathies in reproductive-age women. It often presents during late adolescence but in some cases certain features are evident even before menarche. PCOS is a spectrum of disorders with any combination of oligo/anovulation, clinical and/or biochemical evidence of androgen excess, obesity, insulin resistance and polycystic ovaries on ultrasound. The pathogenesis is unknown; however, it is a complex multigenetic disorder where disordered gonadotropin release, dysregulation of steroidogenesis, hyperinsulinism and insulin resistance play a role. The diagnosis is based on a typical physical exam (acne, hirsutism, obesity, and acanthosis nigricans) and laboratory evidence of hyperandrogenism, such as elevated free testosterone, androstenedione and dehydroepiandrosterone sulfate (DHEAS), decreased sex hormone-binding globulin (SHBG) and increased luteinizing hormone (LH). An ovarian ultrasound may detect the multiple cysts. Secondary causes of PCOS need to be excluded. There are several classes of medications correcting different parameters of PCOS that can be used alone or in combination. Oral contraceptive therapy is
\end{abstract}

used to reduce androgen and LH levels with resultant improvement in acne and hirsutism, and the induction of regular menses. Antiandrogens are usually required for a substantial improvement in hirsutism score. Insulin sensitizers such as metformin are a new class of drugs utilized in treatment of PCOS. By improving insulin sensitivity and decreasing insulin levels, they improve the unfavorable metabolic profile of patients with PCOS. Metformin also helps to increase SHBG, decrease androgen levels and induce ovulation. Despite all the available medications, life-style changes are the mainstay of therapy as weight loss and exercise improve all parameters of PCOS without the potential side effects of medication.

Copyright $\odot 2007$ S. Karger AG, Basel

\section{Introduction}

Polycystic ovary syndrome is one of the most common endocrinopathies in reproductive-age women with an estimated prevalence of $4-12 \%[1,2]$. It represents a spectrum of disorders that consists of chronic anovulation, clinical and/or biochemical evidence of androgen excess and polycystic ovaries on ultrasonography. The chronic anovulation and irregular menses may occur following a period of regular menses; the androgen excess may present with varying degrees of hirsutism, acne, and male-

\section{KARGER}

Fax +4161306 1234 E-Mail karger@karger.ch www.karger.com (c) 2007 S. Karger AG, Basel 0301-0163/07/0685-0209\$23.50/0

Accessible online at:

www.karger.com/hre
Joan DiMartino-Nardi, MD

Pediatric Endocrinology

Albert Einstein College of Medicine, Nortwestern Westchester Hospital

400 East Main Street, Mount Kisco, NY 10549 (USA)

Tel. +1 914242 7337, Fax +1 914242 7646, E-Mail jdimartino2@aol.com 
pattern hair loss; and the polycystic ovaries may or may not be seen on ultrasound. There is substantial evidence that PCOS is a lifelong disorder with first signs emerging before puberty and presenting in certain cases as premature adrenarche (PA) [3-6]. Girls who are born small for gestational age (SGA) are at higher risk for developing PA and consequently PCOS, regardless of their current weight [7]. Because the signs and symptoms are heterogeneous and may vary over time, the diagnosis of PCOS may be delayed.

Furthermore, the onset of the disease and its metabolic component may be influenced by environmental factors such as weight gain. Thus, in addition to the signs and symptoms previously mentioned, the classic patient with PCOS frequently is overweight and has the associated metabolic complications of obesity and insulin resistance.

\section{Pathogenesis}

The precise cause of PCOS is unknown; however, it is considered to be a complex multigenetic disorder characterized by disordered gonadotropin release and dysregulation of steroidogenesis. Hyperinsulinism has also been shown to play a role in the pathogenesis of PCOS and its metabolic component.

\section{Abnormal Pituitary Function}

Disordered regulation of follicle-stimulating hormone (FSH) and luteinizing hormone (LH) release has been implicated in the pathogenesis of PCOS. Under normal circumstances, the hypothalamic gonadotropin-releasing hormone $(\mathrm{GnRH})$ pulses cause $\mathrm{LH}$ and FSH release. $\mathrm{LH}$ then stimulates ovarian theca cells to produce androgens (mainly androstenedione) and FSH stimulates granulosa cells to convert the androstenedione to estrone and estradiol [8]. Estrogen and progesterone provide negative feedback to GnRH-secreting neurons as well as the pituitary. In patients with PCOS, LH is secreted at a higher rate in relation to $\mathrm{FSH}$, with resultant increased thecal production of androgens, specifically androstenedione. More androstenedione is then available for peripheral tissue conversion to testosterone as $17 \beta$-hydroxysteroid dehydrogenase, the enzyme that converts androstenedione to testosterone, is present in most tissues. Androgen excess may counteract the $\mathrm{LH}$-suppressive role of female hormones $[9,10]$ as well as regulation of $\mathrm{GnRH}$ neurons by progesterone [11].

\section{Abnormal Steroidogenesis}

Another hypothesis suggests that PCOS is attributable to intraovarian androgen excess, which arises from functional ovarian hyperandrogenism (FOH) $[12,13]$. Primary $\mathrm{FOH}$ and primary functional adrenal hyperandrogenism (FAH) appear to be caused by dysregulation of steroidogenesis [14]. In contrast to healthy women, where androgens are produced equally from both adrenal glands and ovaries [15], in women with PCOS the ovaries are usually the major source of androgens (especially androstenedione) [14]. Circulating androstenedione is converted to testosterone in peripheral tissues such as adipose tissue and skin.

Increased androgen levels decrease the liver production of sex hormone-binding globulin (SHBG) [16], the major circulating protein that binds testosterone, thus increasing the free (biologically active) testosterone level. These hormonal abnormalities might be related in part to obesity [17].

Dysregulation of ovarian 17 $\alpha$-hydroxylase/17-20 lyase activity in PCOS ovaries has been suggested as a possible intrinsic cause $[12,18]$; however, CYP17 gene structure is normal in PCOS females [19].

\section{Metabolic Component}

Hyperinsulinism resulting from insulin resistance characteristic of central obesity has an important role in the pathogenesis of PCOS at several levels. Insulin has a stimulatory effect on steroidogenesis of normal and polycystic ovaries [20,21]. In addition, high insulin levels increase $\mathrm{LH}$ secretion from the pituitary, elevating the $\mathrm{LH} / \mathrm{FSH}$ ratio, and further contributing to anovulation. Insulin has a direct synergistic effect with LH on the theca cells in enhancing androgen production. In fact, women with PCOS are characterized by the 'insulin paradox', i.e. they are insulin resistant at the level of muscle, adipose tissue and liver, while their ovaries continue to have normal insulin sensitivity [22]. Hyperinsulinism also further decreases SHBG levels, elevating free testosterone [23]. The increased free testosterone level is the cause of the hirsutism, acne and alopecia associated with PCOS.

\section{Diagnosis}

As the clinical features of PCOS are variable, the diagnosis may be delayed in certain women. In addition, there is currently no uniform definition of the syndrome that experts have agreed upon. 
Women with PCOS present with variable degrees of hirsutism, acne, irregular periods, obesity and acanthosis nigricans. Chronic anovulation is associated with increased risk of endometrial hyperplasia and carcinoma as well as infertility. Metabolic consequences of PCOS include the development of impaired glucose tolerance (IGT) and type 2 diabetes mellitus (T2DM), heart disease, hypertension and dyslipidemia. Surprisingly, even lean PCOS patients have a much higher incidence of metabolic disturbances than age- and BMI-matched non-hyperandrogenic controls $[24,25]$.

Secondary causes of hyperandrogenism that respond to specific therapy need to be excluded. These include non-classic congenital adrenal hyperplasia $(\mathrm{CAH})$, hyperprolactinemia, virilizing tumor, exogenous ingestion of anabolic steroids, Cushing's syndrome and extreme forms of insulin resistance (such as insulin receptor mutations).

\section{Family History}

The family history should include information regarding infertility, menstrual disorders and hirsutism in female relatives, early baldness in male relatives, and features of the metabolic syndrome, including obesity, glucose intolerance, diabetes, hypertension, cardiovascular disease and stroke.

\section{Past Medical History}

Past medical history should include birth weight as well as the timing of pubarche, as both low birth weight and premature adrenarche have been identified as risk factors for PCOS. Obese patients should also be screened for the comorbidities of obesity such as obstructive sleep apnea (OSA) symptoms, orthopedic problems, pseudotumor cerebri, diabetes mellitus, non-alcoholic steatohepatitis (NASH), depression, and exercise intolerance.

\section{Physical Exam}

During the physical examination, general body habitus should be noted (gynecoid versus android), as should obesity and fat distribution (i.e. central obesity, dorsal fat pad) with calculation of body mass index, as well as the presence of acne, acanthosis nigricans and male pattern baldness. Severity and distribution of hirsutism is commonly graded using the Ferriman-Gallwey score; in adult women a score of less than 8 is normal [26]. Blood pressure elevation should be noted. The size of the thyroid gland should be evaluated, and a genital exam should be performed to assess the Tanner stage as well as the possibility of virilization. Girls with PCOS should not have signs of virilization such as clitoromegaly, voice change, or a masculine body habitus. The presence of virilizing symptoms and marked hyperandrogenism should alert the physician to the possibility of virilizing adrenal or ovarian tumor or $\mathrm{CAH}$.

\section{Endocrine Evaluation}

The laboratory evaluation should include thyroid function tests (in patients with irregular periods or abnormal thyroid physical exam), total and free testosterone, androstenedione, SHBG levels and dehydroepiandrosterone sulfate (DHEAS). Plasma free testosterone is the single most sensitive test for the detection of androgen excess $[27,28]$, however if total testosterone level is higher than $90 \mathrm{ng} / \mathrm{dl}$, there is a good evidence of androgen excess. Elevated levels of DHEAS are consistent with adrenal hyperandrogenism, as ovaries do not contribute to DHEAS production [19].

Androgen studies should be performed in a laboratory that specializes in endocrine assays [29], the two most sensitive and precise methods are radioimmunoassay (RIA) and tandem mass spectrometry. As direct assays of free testosterone are not reliable, free testosterone should not be measured but calculated from total testosterone and SHBG [30].

Dependent upon the history and physical examination, the initial evaluation may also include the following laboratories to help with exclusion of secondary causes of PCOS-like disorders:

In obese patients, an overnight dexamethasone suppression test (morning cortisol obtained after a dose of dexamethasone $1 \mathrm{mg}$ by mouth at bedtime) can be performed to exclude Cushing's syndrome. A morning cortisol below $2 \mu \mathrm{g} / \mathrm{dl}$ after an evening dose of dexamethasone excludes this diagnosis [31].

In girls with irregular menses, prolactin levels should be measured to exclude a prolactinoma.

Insulin-like growth factor 1 (IGF-1) levels can be obtained if a growth hormone-secreting tumor is suspected. In women with PCOS, the hyperinsulinism may stimulate the IGF-1 receptor with resultant overgrowth and other features mimicking a growth hormone secreting tumor. An IGF-1 level may help to distinguish between the two.

A morning 17-hydroxyprogesterone (17-OHP) level should be obtained to screen for late-onset CAH. 17-OHP of ovarian origin normally rises during the second phase of the menstrual cycle, as, together with progesterone, it is a major product of the corpus luteum. It is often slightly elevated in PCOS (generally, a value $>50 \mathrm{ng} / \mathrm{dl}$ suggests 
hyperandrogenism); however, if the 17-OHP level is $>200$ ng/dl, CAH may be the cause [32], and an ACTH stimulation test (androgens obtained before and $1 \mathrm{~h}$ after the intravenous administration of Cortrosyn $0.25 \mathrm{mg}$ ) should be performed to assess the presence of an enzymatic defect of adrenal steroidogenesis.

\section{Metabolic Screen}

Often the presence of acanthosis nigricans on physical exam is a marker of hyperinsulinism; however, measuring random insulin levels is not useful. An oral glucose tolerance test is recommended in obese patients, as the occurrence of IGT and T2DM is increased in adolescents and women with PCOS compared to their BMI matched controls without PCOS $[25,33]$.

A fasting lipid profile should also be obtained.

\section{Radiographic Studies}

There is currently no agreement on the necessity of obtaining a pelvic ultrasound on all patients unless a tumor is suspected. The presence of polycystic ovaries on ultrasonography is not required to establish the diagnosis of PCOS; furthermore, the presence of cysts on ultrasound does not indicate the presence of PCOS. Polycystic ovaries on ultrasound are only found in 55\% of adolescents and $75 \%$ of adult woman [34]. A vaginal ultrasound is more appropriate for ovarian imaging; however this technique is not used in virginal patients.

In patients with rapidly developing symptomatology and/or signs of virilization such as clitoromegaly, deepening of the voice, or a masculine body habitus, a virilizing tumor should be suspected, and visualization of the adrenals and ovaries by ultrasound, CT scanning or MRI should be obtained. CT scanning is the preferred method for adrenal pathology and ultrasound for ovarian. Marked hyperandrogenism, such as a total testosterone level of $>200 \mathrm{ng} / \mathrm{dl}$ or DHEAS of $>700 \mu \mathrm{g} / \mathrm{dl}$, is highly suspicious and should also prompt imaging to evaluate for a possible tumor.

\section{Treatment}

The purpose of therapy for PCOS is to reduce hyperandrogenism in order to improve hirsutism and acne, restore regular ovulatory cycles, and correct the metabolic syndrome features.

The course of treatment for women with PCOS largely depends on the severity of the symptoms and the specific goals to be achieved. For example, in the young woman interested in conceiving, a goal of therapy would be to induce ovulation. The patient who is hirsute will be concerned with decreasing their androgen levels.

Adolescents with PCOS tend to be troubled most by the cosmetic effects of PCOS, such as acne, hirsutism, and/or acanthosis nigricans. These symptoms are disturbing to them as they occur during a particularly vulnerable stage of their psychological development - when appearance and acceptance by peers is of utmost importance. Their treatment must address these issues as well as take into account the long-term consequences, such as the risk of developing metabolic and cardiovascular abnormalities.

\section{Life-Style Modification}

The most preferred and effective method of treatment for obese adolescents with PCOS is lifestyle modification; however, it is also the hardest for patients to comply with and achieve. Weight loss improves practically every parameter of PCOS [35]. Healthy diet and regular exercise are the most beneficial therapies in treating PCOS symptoms and preventing future complications. Minimal weight loss of $2-7 \%$ of body weight reduces androgen levels and improves ovulatory function in many patients with PCOS $[36,37]$.

While a low fat/high carbohydrate diet is traditionally thought to improve metabolic and reproductive function due to weight loss, a high-protein/low-carbohydrate diet increases weight loss due to the increased satiating power of protein compared with carbohydrate or fat and may improve insulin sensitivity through maintenance of lean body mass with weight loss. Carbohydrate restriction versus fats restriction is generally considered advantageous; however, several recent studies did not show a distinct benefit from calorie-restricted diets limiting carbohydrates rather than fat $[38,39]$. A high protein/low carbohydrate diet may be useful in the management of PCOS; however, improvements of clinical parameters occur maximally in energy restriction and are maintained or reversed during weight maintenance. Although enhanced reproductive function may be induced by caloric deficit and relatively small weight loss, the maintenance of weight is critical for reduced complications. This mode of treatment is effective, cheap and has no side effects.

For patients not able to achieve a therapeutic weight reduction, life-style changes should be combined with pharmacotherapy. Traditionally, pharmacological agents available for the treatment of hirsutism include androgen suppressors and peripheral androgen blockers. 
Table 1. Therapeutic options for PCOS and its components

\begin{tabular}{|c|c|c|c|c|c|c|}
\hline & $\begin{array}{l}\text { Weight } \\
\text { reduction }\end{array}$ & OCP & Antiandrogens & Metformin & Glucocorticoids & $\begin{array}{l}\text { Topical } \\
\text { treatment }\end{array}$ \\
\hline $\begin{array}{l}\text { Irregular } \\
\text { periods }\end{array}$ & $\begin{array}{l}\text { Improves } \\
\text { regularity }\end{array}$ & $\begin{array}{l}\text { First line } \\
\text { Induces regular } \\
\text { anovulatory cycles }\end{array}$ & & Improves regularity & & \\
\hline $\begin{array}{l}\text { Ovulation/ } \\
\text { fertility }\end{array}$ & $\begin{array}{l}\text { May induce } \\
\text { ovulation }\end{array}$ & $\begin{array}{l}\text { Suppresses } \\
\text { ovulation }\end{array}$ & $\begin{array}{l}\text { May induce } \\
\text { ovulation }\end{array}$ & May induce ovulation & & \\
\hline $\begin{array}{l}\text { Hyperandro- } \\
\text { genism } \\
\text { ovarian }(\mathrm{FOH})\end{array}$ & Decreases & $\begin{array}{l}\text { Suppresses plasma } \\
\text { androgens, especially } \\
\text { free testosterone } \\
\text { (normal levels of } \\
\text { androgens within } \\
3 \text { months) }\end{array}$ & $\begin{array}{l}\text { Decreases } \\
\text { (spironolactone) }\end{array}$ & $\begin{array}{l}\text { Decreases androgen } \\
\text { levels by up to } 20 \%\end{array}$ & decreases & \\
\hline $\begin{array}{l}\text { Hyperandro- } \\
\text { genism } \\
\text { adrenal (FAH) }\end{array}$ & Decreases & $\begin{array}{l}\text { Slight decrease in } \\
\text { DHEAS }\end{array}$ & $\begin{array}{l}\text { Decreases } \\
\text { (spironolactone) }\end{array}$ & & $\begin{array}{l}\text { In non-obese predominantly } \\
\text { FAH and failed OCP } \\
5-7.5 \text { mg of prednisone qHS } \\
\text { to suppress androgens below } \\
\text { adult range but not completel } \\
\text { (3-month trial) }\end{array}$ & \\
\hline $\begin{array}{l}\text { Obesity/ } \\
\text { metabolic } \\
\text { consequences }\end{array}$ & $\begin{array}{l}\text { First line } \\
\text { Improves all } \\
\text { parameters with } \\
\text { minimal weight } \\
\text { loss (5\%) } \\
\text { Increases SHBG }\end{array}$ & $\begin{array}{l}\text { Increases SHBG } \\
\text { Does not cause } \\
\text { weight gain }\end{array}$ & May have a modest effect & $\begin{array}{l}\text { First line } \\
\text { Improves metabolic } \\
\text { profile } \\
\text { Increases SHBG } \\
\text { Consider using with } \\
\text { OCP because of } \\
\text { improved ovulation } \\
\text { and increased fertility }\end{array}$ & no effect & \\
\hline Hirsutism & $\begin{array}{l}\text { Gradual reduc- } \\
\text { tion within } \\
6 \text { months of } \\
\text { weight loss }\end{array}$ & $\begin{array}{l}\text { Arrests progres- } \\
\text { sion, gradual } \\
\text { reduction }\end{array}$ & $\begin{array}{l}\text { First line } \\
\text { (in severe cases) } \\
\text { Effect seen in } 9-12 \text { months } \\
\text { (F-G score decreases by } \\
30-50 \% \text { ) } \\
\text { Must be prescribed with } \\
\text { OCP because of risk of } \\
\text { incomplete virilization of } \\
\text { male fetus }\end{array}$ & Gradual reduction & $\begin{array}{l}\text { Gradual reduction in } \\
\text { F-G score }\end{array}$ & $\begin{array}{l}\text { Mild cases } \\
\text { or as an add-on } \\
\text { treatment } \\
\text { before maxi- } \\
\text { mum effect } \\
\text { of oral therapy } \\
\text { is seen }\end{array}$ \\
\hline Acne & Improves & $\begin{array}{l}\text { Improves within } \\
3 \text { months }\end{array}$ & $\begin{array}{l}\text { Improvement in } \\
3-5 \text { months }\end{array}$ & & & $\begin{array}{l}\text { Mild cases or } \\
\text { as an adjunct } \\
\text { therapy }\end{array}$ \\
\hline
\end{tabular}

\section{Hormonal Treatment}

Estrogen-progestin combination therapy remains the predominant treatment for reduction of hyperandrogenism and resultant improvements of hirsutism and acne as well as menstrual irregularities (table 1).

The estrogenic component suppresses luteinizing hormone and thus androgen production from the ovary, and enhances hepatic production of SHBG, thereby reducing free plasma testosterone.

Various progestins are utilized in oral contraceptive pills (OCPs), with some progestins having more andro- genic activity than others. Norgestimate, desogestrel and gestodene are considered to have low androgenic potential, whereas levonorgestrel and norgestrel have high androgenic activity. At this time, clinical studies have not shown that a lower androgenic progestin is more effective for the treatment of hirsutism. Nevertheless, most pediatric endocrinologist still prefer to use OCPs with low androgenic potential such as Demulen $1 / 50^{\circledR}$ (useful in obese patients, who require higher doses of estrogen), Ortho-Tri-Cyclen ${ }^{\circledR}$ (FDA approved for treatment of acne in women) or Yasmin ${ }^{\circledR}$, which contains drospirenone (spi- 
ronolactone-related, anti-mineralocorticoid with antiandrogenic activity).

OCP therapy should continue until gynecological maturity is reached ( 5 years post-menarche) or substantial weight loss has been achieved. Treatment can then be withheld for a few months to assess the function of the pituitary-gonadal axis and recovery of spontaneous periods [14]. Positive effects of OCP therapy should be noticeable after 3 months, with normalization of periods and improvement of acne and hirsutism (arrest of progression, reduction in shaving frequency). Studies have shown that suppression of serum androgens can continue for up to 2 years after discontinuation of OCPs (this is a controversial point, as most patients return to baseline results after 3 months of discontinued therapy).

Potential side effects include alterations in insulin action, vascular reactivity and hypercoagulativity. OCPs should be used with caution and in the lowest estrogen dose possible in patients with a history of migraine headaches [40]. Contrary to popular opinion, OCPs do not cause weight gain or increase of body fat in teenagers with PCOS [41].

\section{Antiandrogens}

Antiandrogens are usually required to substantially improve the hirsutism score. They act as competitive antagonists of steroid binding to the androgen receptor and reverse the androgen-induced transformation of vellus to terminal hairs [42]. Because of the long growth cycle of the terminal hair, the full effect is not appreciated until 9-12 months after the beginning of treatment. All antiandrogens should be prescribed together with a contraceptive because they can cause incomplete virilization of a male fetus as well as menstrual irregularities. Antiandrogens have only a modest effect on the metabolic abnormalities associated with PCOS [43].

Cyproterone acetate is a progestin with antiandrogenic activity that competitively inhibits binding of testosterone and $5 \alpha$-dihydrotestosterone (DHT) to the androgen receptor. It is paired with ethinyl estradiol in a combination estrogen-progestin therapy $\left(\right.$ Diane $\left.^{\circledR}\right)$ that is widely used throughout Europe, Canada and Mexico and has achieved excellent results in reduction of hirsutism score and acne after 9 months of treatment [44]. However, due to a possibility of higher thrombogenic potential of the Diane ${ }^{\circledR}$ pill, it should only be prescribed for patients with severe hirsutism and acne and not solely as a contraceptive agent. The dose of cyproterone acetate in Diane ${ }^{\circledR}$ is $2 \mathrm{mg}$, but in the treatment of PCOS the dosing can go up to $25-50 \mathrm{mg}$ daily. Cyproterone acetate is not available in the United States.

Spironolactone, an aldosterone antagonist, has multiple antiandrogenic effects including inhibition of ovarian and adrenal androgen production, blockage of DHT binding to skin androgen receptors, elevation of SHBG levels, increased testosterone clearance from the body, and decreased $5 \alpha$-reductase activity.

The effectiveness of spironolactone in hirsute women is related to the utilized dose, as it possesses moderate antiandrogenic effects in large doses $(200 \mathrm{mg} /$ day divided twice daily) [45]. An initial dose of $100 \mathrm{mg}$ a day is considered appropriate for the lean hirsute woman, but higher daily doses of 200 or $300 \mathrm{mg}$ might be necessary for the successful treatment of a woman who is severely hirsute or obese.

Side effects include polydipsia, polyuria, nausea, headaches, fatigue, gastritis and ovulatory dysfunction resulting in polymenorrhea. Because of its action as an aldosterone antagonist, spironolactone is also a diuretic and has the potential to cause hyperkalemia. For the healthy young PCOS patient, hyperkalemia remains a theoretical concern, because this complication has been reported only in patients who are elderly, diabetic, on medications that can raise potassium levels, or who have impaired renal function. To minimize side effects, a starting dose of $25 \mathrm{mg}$ /day should be increased over several weeks.

Spironolactone should be given for at least 6 months to gain maximum improvement in hirsutism. The maintenance dose can then be dropped to 25-100 mg daily, with overweight women requiring the higher dose.

Spironolactone has also been shown to decrease sebum production and improve acne. The therapeutic dose range for acne therapy is $50-100 \mathrm{mg}$ a day, with some women having positive effects with only $25 \mathrm{mg}$ daily.

As mentioned above, the addition of an OCP to spironolactone therapy is recommended for contraceptive purposes, as incomplete virilization of a male fetus and irregular bleeding may occur as a result of this medication. Also, dermatologists have recommended the addition of spironolactone to OCP treatment for severely affected adult women, because it will result in an increased therapeutic benefit to the skin.

The dose of drospirenone in Yasmin ${ }^{\circledR}$ is equivalent to $25 \mathrm{mg}$ of spironolactone.

Flutamide, a potent nonsteroidal antiandrogen, is very effective in treatment of hirsutism [46]. However, it has a minimal indication in the adolescent patient because of its potential dose-dependent hepatotoxicity and high cost. 
Finasteride, an inhibitor of type $25 \alpha$-reductase, has been reported to treat hirsutism [46]. It blocks conversion of testosterone to the more potent DHT. Since the pilosebaceous unit has predominantly the type $15 \alpha$-reductase enzyme, it is unlikely to become the optimal treatment of the androgen-related skin manifestation of PCOS [47]. It is less effective for hirsutism than antiandrogens [48].

Neither flutamide nor finasteride are FDA approved for treatment of hirsutism.

\section{Glucocorticoids}

Glucocorticoids may be indicated for women whose PCOS-like features are secondary to late-onset $\mathrm{CAH}$ and for those with marked adrenal androgen excess. A modest dose (5-7.5 mg of prednisone) given at bedtime reduces the secretion of adrenal androgens more than that of cortisol and minimizes the sequelae of glucocorticoid therapy. The aim is to suppress DHEAS below the adult range but not completely [14].

\section{Cosmetic Treatment}

The above-mentioned treatment options are often accompanied by cosmetic and dermatologic treatment including depilation, epilation or destruction of the dermal papilla with electrolysis or laser. This last-mentioned technique is painful and expensive, and thus practical only for treatment of limited areas. The newest addition to the topical armamentarium is eflornithine hydrochloride $13.9 \%$ (Vaniqua $^{\circledR}$ ) which has been recently approved for the treatment of hirsutism [49]. However, the hair will grow back after discontinuation of this treatment.

\section{Insulin Sensitizers}

While traditional treatments with OCPs and anti-androgens correct menstrual irregularity and hyperandrogenemia - and consequently acne and hirsutism - they have no effect on insulin resistance, hyperinsulinism and their metabolic consequences. This shortcoming is now coming to the forefront of specialists' attention. Our understanding of the role of insulin resistance has led to the use of insulin-sensitizing medications as the first-choice therapy in obese adolescents. In conjunction with weight reduction, a pharmacologic reduction in insulin levels by either metformin or thiazolidinediones ameliorates both hyperinsulinism and hyperandrogenism.

Metformin acts primarily by inhibiting hepatic glucose output and increasing insulin sensitivity in peripheral tissues [50]. Insulin levels decrease and this results in a decrease in the levels of androgens and $\mathrm{LH}$ and an increase in SHBG, further decreasing free testosterone levels. As beneficial as metformin can be for adult women with PCOS, it appears even more effective in adolescents with this condition. Hyperinsulinemia and hyperandrogenism improve just as much as in adults, but there is an even higher rate at normalizing menses and decreasing hirsutism score in teenagers and young adults [5153]. Metformin administration has been linked to significantly improved insulin levels and regularized menstrual cycles in oligo-amenorrheic teenagers with PCOS [54]. A small, randomized, double blind, placebo-controlled trial of metformin in morbidly obese adolescents showed significant changes in BMI, fasting blood glucose and insulin levels. Furthermore, treatment for 6-12 months was followed by significant reductions in serum lipid levels (reduction in total cholesterol, LDL and triglycerides and increase in HDL) and hirsutism score [53]. Metformin treatment was also found to correct anovulatory cycles and induce ovulation and regular periods in nonobese teenagers with PCOS [55].

The recommended starting dose is $500 \mathrm{mg}$ with dinner, to be increased by $500 \mathrm{mg}$ weekly, as tolerated, to a maximum dose of 2,000 mg daily, divided into 2 doses for better tolerance in the larger doses. Patients need to be aware that it is not a weight-loss drug; however, it can enhance weight loss by suppressing appetite [56]. Metformin use in the treatment of PCOS may be lifelong. It has been shown that all the improvements were lost 3 months after cessation of metformin treatment [53].

As mentioned above, data have shown that the use of these agents is associated with improvement of spontaneous ovulation, and therefore the risk of pregnancy increases. If pregnancy is undesirable, as in most adolescents, this risk has to be conveyed to the adolescent prior to initiation therapy, and appropriate steps should be taken to prevent conception.

Thiazolidinediones are another class of insulin-sensitizing medications that are potentially effective in treatment of PCOS. They act by improving insulin action and glucose utilization at the level of liver, skeletal muscle and adipose tissue, and they have a modest effect on hepatic glucose production. Pioglitazone has been shown to improve androgen and lipid profiles as well as insulin secretion and sensitivity in obese PCOS women [57]. Unfortunately, this class of drugs tends to cause weight gain.

Insulin sensitizers should always be used as an adjuvant to general lifestyle improvements and not as a replacement for increased exercise and better diet. 


\section{Conclusions}

Current dietetic and medical advice should continue to focus on weight loss and healthy life-style as an important treatment goal in overweight women with PCOS in order to reduce the long-term risks of diabetes and cardiovascular disease.

Even though several treatment options exist, we recommend the use of OCP, especially if the adolescent is interested in birth control, spironolactone for the treatment of hirsutism, and the highly effective metformin if there is obesity and evidence of insulin resistance. These are prescribed with emphasis on the fact that healthy diet and regular exercise are the best way to treat PCOS symptoms and prevent complications of obesity and insulin resistance.

\section{References}

-1 Knochenhauer ES, Key TJ, Kahsar-Miller M, Waggoner W, Boots LR, Azziz R: Prevalence of the polycystic ovary syndrome in unselected black and white women of the southeastern United States: a prospective study. J Clin Endocrinol Metab 1998;83:3078-3082.

$\checkmark 2$ Kent SC, Legro RS: Polycystic ovary syndrome in adolescents. Adolesc Med 2002;13: $73-88$, vi.

-3 Meas T, Chevenne D, Thibaud E, Leger J, Cabrol S, Czernichow P, Levy-Marchal C: Endocrineconsequences of prematurepubarche in post-pubertal Caucasian girls. Clin Endocrinol (Oxf) 2002;57:101-106.

4 Ibanez L, Potau N, Virdis R, Zampolli M, Terzi C, Gussinye M, Carrascosa A, VicensCalvet E: Postpubertal outcome in girls diagnosed of premature pubarche during childhood: increased frequency of functional ovarian hyperandrogenism. J Clin Endocrinol Metab 1993;76:1599-1603.

5 Dimartino-Nardi J: Premature adrenarche: findings in prepubertal African-American and Caribbean-Hispanic girls. Acta Paediatr Suppl 1999;88:67-72.

-6 Vuguin P, Linder B, Rosenfeld RG, Saenger P, DiMartino-Nardi J: The roles of insulin sensitivity, insulin-like growth factor I (IGFI), and IGF-binding protein- 1 and -3 in the hyperandrogenism of African-American and Caribbean Hispanic girls with premature adrenarche. J Clin Endocrinol Metab 1999;84:2037-2042.

7 Ibanez L, Potau N, Francois I, de Zegher F: Precocious pubarche, hyperinsulinism, and ovarian hyperandrogenism in girls: relation to reduced fetal growth. J Clin Endocrinol Metab 1998;83:3558-3562.

-8 McNatty KP, Makris A, DeGrazia C, Osathanondh R, Ryan KJ: The production of progesterone, androgens, and estrogens by granulosa cells, thecal tissue, and stromal tissue from human ovaries in vitro. J Clin Endocrinol Metab 1979;49:687-699.

-9 Berga SL, Guzick DS, Winters SJ: Increased luteinizing hormone and alpha-subunit secretion in women with hyperandrogenic anovulation. J Clin Endocrinol Metab 1993;77: 895-901.
10 Eagleson CA, Gingrich MB, Pastor CL, Arora TK, Burt CM, Evans WS, Marshall JC: Polycystic ovarian syndrome: evidence that flutamide restores sensitivity of the gonadotropin-releasing hormone pulse generator to inhibition by estradiol and progesterone. J Clin Endocrinol Metab 2000;85:4047-4052.

-11 Turgeon JL, Waring DW: Androgen modulation of luteinizing hormone secretion by female rat gonadotropes. Endocrinology 1999; 140:1767-1774.

12 Ehrmann DA, Barnes RB, Rosenfield RL: Polycystic ovary syndrome as a form of functional ovarian hyperandrogenism due to dysregulation of androgen secretion. Endocr Rev 1995;16:322-353.

13 Rosenfield RL: Ovarian and adrenal function in polycystic ovary syndrome. Endocrinol Metab Clin N Am 1999;28:265-293.

14 Buggs C, Rosenfield RL: Polycystic ovary syndrome in adolescence. Endocrinol Metab Clin N Am 2005;34:677-705, x.

15 Longcope C: Adrenal and gonadal androgen secretion in normal females. Clin Endocrinol Metab 1986;15:213-228.

16 Edmunds SE, Stubbs AP, Santos AA, Wilkinson ML: Estrogen and androgen regulation of sex hormone binding globulin secretion by a human liver cell line. J Steroid Biochem Mol Biol 1990;37:733-739.

17 Penttila TL, Koskinen P, Penttila TA, Anttila L, Irjala K: Obesity regulates bioavailable testosterone levels in women with or without polycystic ovary syndrome. Fertil Steril 1999;71:457-461.

18 Gilling-Smith C, Story H, Rogers V, Franks S: Evidence for a primary abnormality of thecal cell steroidogenesis in the polycystic ovary syndrome. Clin Endocrinol (Oxf) 1997;47:93-99.

19 Pang S: Pediatric Endocrinology, ed 4. New York, Marcel Dekker, 2003.

20 Franks S, Gilling-Smith C, Watson H, Willis D: Insulin action in the normal and polycystic ovary. Endocrinol Metab Clin N Am 1999;28:361-378.
21 Nestler JE, Jakubowicz DJ, de Vargas AF, Brik C, Quintero N, Medina F: Insulin stimulates testosterone biosynthesis by human thecal cells from women with polycystic ovary syndrome by activating its own receptor and using inositolglycan mediators as the signal transduction system. J Clin Endocrinol Metab 1998;83:2001-2005.

22 Willis D, Franks S: Insulin action in human granulosa cells from normal and polycystic ovaries is mediated by the insulin receptor and not the type-I insulin-like growth factor receptor. J Clin Endocrinol Metab 1995;80: 3788-3790.

23 Loukovaara M, Carson M, Adlercreutz H: Regulation of production and secretion of sex hormone-binding globulin in HepG2 cell cultures by hormones and growth factors. J Clin Endocrinol Metab 1995;80:160164.

24 Coviello AD, Legro RS, Dunaif A: Adolescent girls with polycystic ovary syndrome have an increased risk of the metabolic syndrome associated with increasing androgen levels independent of obesity and insulin resistance. J Clin Endocrinol Metab 2006;91: 492-497.

-25 Legro RS, Kunselman AR, Dodson WC, Dunaif A: Prevalence and predictors of risk for type 2 diabetes mellitus and impaired glucose tolerance in polycystic ovary syndrome: a prospective, controlled study in 254 affected women. J Clin Endocrinol Metab 1999;84: 165-169.

26 Hatch R, Rosenfield RL, Kim MH, Tredway D: Hirsutism: implications, etiology, and management. Am J Obstet Gynecol 1981; 140:815-830.

27 Moll GW Jr, Rosenfield RL: Testosterone binding and free plasma androgen concentrations under physiological conditions: characterization by flow dialysis technique. J Clin Endocrinol Metab 1979;49:730-736.

28 Wild RA, Umstot ES, Andersen RN, Ranney GB, Givens JR: Androgen parameters and their correlation with body weight in one hundred thirty-eight women thought to have hyperandrogenism. Am J Obstet Gynecol 1983;146:602-606. 
-29 Goodman NF, Bledsoe MB, Futterweit W, Goldzieher JW, Petak SM, Smith KD, Steinberger E, Anderson RJ, Bergman DA, Bloomgarden ZT, Dickey RA, Palumbo PJ, Peters AL, Rettinger HI, Rodbard HW, Rubenstein HA: American Association of Clinical Endocrinologists medical guidelines for the clinical practice for the diagnosis and treatment of hyperandrogenic disorders. Endocr Pract 2001;7:120-134.

>30 Miller KK, Rosner W, Lee H, Hier J, Sesmilo G, Schoenfeld D, Neubauer G, Klibanski A: Measurement of free testosterone in normal women and women with androgen deficiency: comparison of methods. J Clin Endocrinol Metab 2004;89:525-533.

$\checkmark 31$ Blethen SL, Chasalow FI: Overnight dexamethasone suppression test: normal responses and the diagnosis of Cushing's syndrome. Steroids 1989;54:185-193.

-32 Azziz R, Dewailly D, Owerbach D: Clinical review 56. Nonclassic adrenal hyperplasia: current concepts. J Clin Endocrinol Metab 1994;78:810-815.

33 Lewy VD, Danadian K, Witchel SF, Arslanian S: Early metabolic abnormalities in adolescent girls with polycystic ovarian syndrome. J Pediatr 2001;138:38-44.

-34 Rosenfield RL, Ghai K, Ehrmann DA, Barnes RB: Diagnosis of the polycystic ovary syndrome in adolescence: comparison of adolescent and adult hyperandrogenism. J Pediatr Endocrinol Metab 2000;13(suppl 5):12851289.

\35 Salmi DJ, Zisser HC, Jovanovic L: Screening for and treatment of polycystic ovary syndrome in teenagers. Exp Biol Med (Maywood) 2004;229:369-377.

>36 Huber-Buchholz MM, Carey DG, Norman RJ: Restoration of reproductive potential by lifestyle modification in obese polycystic ovary syndrome: role of insulin sensitivity and luteinizing hormone. J Clin Endocrinol Metab 1999;84:1470-1474.

-37 Hoeger KM, Kochman L, Wixom N, Craig K, Miller RK, Guzick DS: A randomized, 48week, placebo-controlled trial of intensive lifestyle modification and/or metformin therapy in overweight women with polycystic ovary syndrome: a pilot study. Fertil Steril 2004;82:421-429.
38 Moran LJ, Noakes M, Clifton PM, Tomlinson L, Galletly C, Norman RJ: Dietary composition in restoring reproductive and metabolic physiology in overweight women with polycystic ovary syndrome. J Clin Endocrinol Metab 2003;88:812-819.

39 Stamets K, Taylor DS, Kunselman A, Demers LM, Pelkman CL, Legro RS: A randomized trial of the effects of two types of short-term hypocaloric diets on weight loss in women with polycystic ovary syndrome. Fertil Steril 2004;81:630-637.

40 Lidegaard O: Oral contraceptives, pregnancy and the risk of cerebral thromboembolism: the influence of diabetes, hypertension, migraine and previous thrombotic disease. Br J Obstet Gynaecol 1995;102:153-159.

41 Lloyd T, Lin HM, Matthews AE, Bentley CM, Legro RS: Oral contraceptive use by teenage women does not affect body composition. Obstet Gynecol 2002;100:235-239.

42 Deplewski D, Rosenfield RL: Role of hormones in pilosebaceous unit development. Endocr Rev 2000;21:363-392.

43 Ibanez L, Potau N, Marcos MV, de Zegher F: Treatment of hirsutism, hyperandrogenism, oligomenorrhea, dyslipidemia, and hyperinsulinism in nonobese, adolescent girls: effect of flutamide. J Clin Endocrinol Metab 2000; 85:3251-3255.

44 van Wayjen RG, van den Ende A: Experience in the long-term treatment of patients with hirsutism and/or acne with cyproterone acetate-containing preparations: efficacy, metabolic and endocrine effects. Exp Clin Endocrinol Diabetes 1995;103:241-251.

45 Spritzer PM, Lisboa KO, Mattiello S, Lhullier F: Spironolactone as a single agent for longterm therapy of hirsute patients. Clin Endocrinol (Oxf) 2000;52:587-594.

46 Falsetti L, Gambera A, Legrenzi L, Iacobello C, Bugari G: Comparison of finasteride versus flutamide in the treatment of hirsutism. Eur J Endocrinol 1999;141:361-367.

47 Ehrmann DA: Polycystic ovary syndrome. N Engl J Med 2005;352:1223-1236.

48 Farquhar C, Lee O, Toomath R, Jepson R: Spironolactone versus placebo or in combination with steroids for hirsutism and/or acne. Cochrane Database Syst Rev 2003: CD000194.
49 Balfour JA, McClellan K: Topical eflornithine. Am J Clin Dermatol 2001;2:197-201; discussion 202.

50 Kirpichnikov D, McFarlane SI, Sowers JR: Metformin: an update. Ann Intern Med 2002; 137:25-33.

51 Arslanian SA, Lewy V, Danadian K, Saad R: Metformin therapy in obese adolescents with polycystic ovary syndrome and impaired glucose tolerance: amelioration of exaggerated adrenal response to adrenocorticotropin with reduction of insulinemia/ insulin resistance. J Clin Endocrinol Metab 2002;87:1555-1559.

52 Loverro G, Lorusso F, De Pergola G, Nicolardi V, Mei L, Selvaggi L: Clinical and endocrinological effects of 6 months of metformin treatment in young hyperinsulinemic patients affected by polycystic ovary syndrome. Gynecol Endocrinol 2002;16:217224.

53 Ibanez L, Valls C, Potau N, Marcos MV, de Zegher F: Sensitization to insulin in adolescent girls to normalize hirsutism, hyperandrogenism, oligomenorrhea, dyslipidemia, and hyperinsulinism after precocious pubarche. J Clin Endocrinol Metab 2000;85: 3526-3530.

54 Glueck CJ, Wang P, Fontaine R, Tracy T, Sieve-Smith L: Metformin to restore normal menses in oligo-amenorrheic teenage girls with polycystic ovary syndrome (PCOS). J Adolesc Health 2001;29:160-169.

-55 Ibanez L, Valls C, Ferrer A, Marcos MV, Rodriguez-Hierro F, de Zegher F: Sensitization to insulin induces ovulation in nonobese adolescents with anovulatory hyperandrogenism. J Clin Endocrinol Metab 2001;86:35953598.

>56 Ibanez L, Valls C, Marcos MV, Ong K, Dunger DB, De Zegher F: Insulin sensitization for girls with precocious pubarche and with risk for polycystic ovary syndrome: effects of prepubertal initiation and postpubertal discontinuation of metformin treatment. J Clin Endocrinol Metab 2004;89:4331-4337.

57 Romualdi D, Guido M, Ciampelli M, Giuliani M, Leoni F, Perri C, Lanzone A: Selective effects of pioglitazone on insulin and androgen abnormalities in normo- and hyperinsulinaemic obese patients with polycystic ovary syndrome. Hum Reprod 2003; 18:1210-1218. 